\title{
Dr. Henning A. Gaissert: because tracheal surgical techniques remain imperfect, international cooperation is needed to strive for improvement
}

Received: 07 November 2018; Accepted: 11 December 2018; Published: 27 December 2018.

doi: $10.21037 /$ shc.2018.12.09

View this article at: http://dx.doi.org/10.21037/shc.2018.12.09

\section{Editor's note}

The $9^{\text {th }}$ National Trachea Surgery Conference was successfully held in Shanghai on November $10^{\text {th }}, 2018$, gathering many renowned experts and surgeons from home and abroad to exchange new ideas and techniques in trachea surgery.

During the meeting, Dr. Henning A. Gaissert (Figure 1), from Massachusetts General Hospital (USA), gave a lecture on "Tracheal reconstruction after failed intervention". Seizing this opportunity, we are honored to have Dr. Gaissert for an interview.

At the outset, Dr. Gaissert said he had visited Shanghai Chest Hospital and was very impressed by the volume and safe conduct of chest operations and the seamless cooperation between surgeons and doctors from different departments. In addition, he commented on the excellent organization of the meeting and recognized that Chinese surgeons profoundly value history, which he thought sets a good example for his people.

In discussing the current status and future direction of his hospital's research in primary tracheal tumors, Gaissert told us that challenges remained despite some breakthroughs due to the lack of reliable tracheal replacement. He pointed out the difficulties to obtain complete resection of tracheal tumors because of the constraints of mediastinal anatomy. Gaissert praised Chinese surgeons for establishing safe minimally invasive techniques in tracheal resection. Caution may be appropriate when surgeons change the surgical approach to make it less invasive, to avoid compromising complete resection of tumors. Dr. Gaissert expressed concern that if surgeons are too obsessed with the goal of rapid recovery, it may compromise surgical techniques. $\mathrm{He}$ stated his confidence that Chinese surgeons will represent the leading edge of future improvements in tracheal surgery.

Malignant airway tumors present particular challenges. For current optimal management, Dr. Gaissert favored

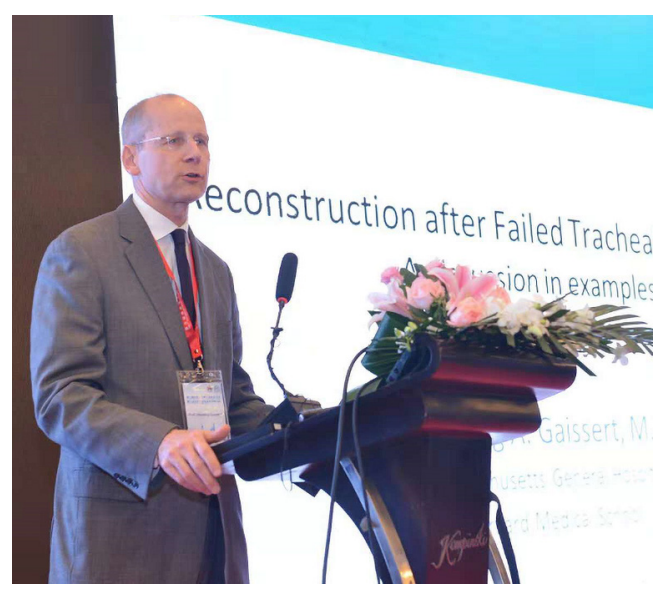

Figure 1 Dr. Henning A. Gaissert.

the creation of national referral centers to achieve the best outcomes for the benefit of patients and to best support surgeon education; national referral centers would connect advanced knowledge and research organizations in different areas and countries to provide the best medical service for patients with these challenging tumors and diseases. A cooperative spirit between countries he believes would create the best opportunity to disseminate optimal management and promote the therapy of the future.

Recently, the Society of Thoracic Surgeons National Database 2018 Annual Report was released. Regarding how to better construct China's database in thoracic disease, Dr. Gaissert, a co-author of this report, shared with us the clinical benefits of a national database. Beyond the important function of collecting a national repository of contemporary standards, the Thoracic National Database serves as a platform for surgeons to openly discuss and share experiences with the goal of raising the quality of treatment across the nation and start initiatives to improve patient care. Quality measures include, for example, whether 


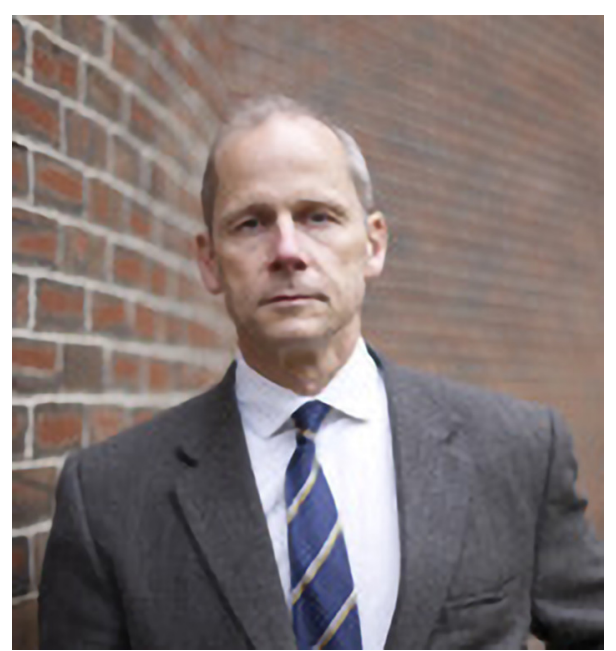

Figure 2 Henning A. Gaissert, Division of Thoracic Surgery, Department of Surgery, Massachusetts General Hospital, Boston, MA, USA.

prophylactic antibiotics are given at the appropriate time and whether prevention of pulmonary embolism is practiced.

At the end of our interview, Dr. Gaissert delightedly shared with us his advice for the young medical students who want to be successful in his field.

To be a successful surgeon is a long and arduous journey. Many find it difficult and some consider giving up at the beginning. When students uncertain of their career path seek help, Dr. Gaissert will do his best to discover their passion. He also emphasized that the young generation cannot simply follow in the older generation's footsteps, but must break new paths. Dr. Gaissert is excited about the next generation. He said they have the enthusiasm for learning knowledge and new techniques and possess the strength to chart a different course, a quality that encourages him. $\mathrm{He}$ believes that this generation of medical students holds great promise and shows great potential to catalyze the advance of medical science and technology.

\section{Expert introduction}

Prof. Henning A. Gaissert (Figure 2) graduated from Technical University of Munich, Germany, in 1984 before entering internship and residency in General Surgery at Massachusetts General Hospital and Harvard Medical School, Boston, Massachusetts, and Barnes-Jewish Hospital and Washington University, St. Louis, Missouri. Following

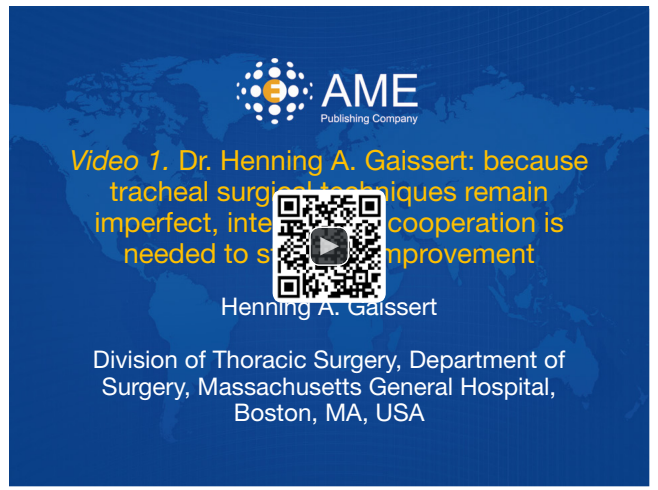

Figure 3 Dr. Henning A. Gaissert: because tracheal surgical techniques remain imperfect, international cooperation is needed to strive for improvement (1).

Available online: http://www.asvide.com/article/view/29067

his fellowship in Thoracic Surgery at Washington University, he became Chief of Thoracic Surgery at Rhode Island Hospital and Brown University in Providence, Rhode Island, in 1995 before returning to Massachusetts General Hospital in 2001 where he is an Associate Professor of Surgery and Chief of Thoracic Surgery at Newton-Wellesley Hospital. Dr. Gaissert's interest includes minimally and maximally invasive surgical treatment of lung cancer, surgical reconstruction of the large airways and reoperative foregut surgery.

\section{Interview questions (Figure 3)}

(I) What do you most expect to see during the meeting?

(II) Would you like to talk about the current status and future direction of your research in primary tracheal tumors?

(III) Malignant airway tumor still is a big challenge. What's the ideal surgical management in your opinion?

(IV) The Center for Thoracic Cancers at MGH was one of the first in the country to use novel targeted therapies for certain types of chest cancer. Compared with traditional treatment, what are the advantages and limitations of this innovative approach?

(V) Recently, The Society of Thoracic Surgeons National Database 2018 Annual Report has released. For cardiothoracic surgeons, would you like to talk about the significance of the STS National Database? Regarding how to better construct Chinese database in thoracic disease, what's your advice? 
(VI) What message you would like to send to the young medical students who want to be successful in you field?

\section{Acknowledgments}

Funding: None.

\section{Footnote}

Provenance and Peer Review: This article was commissioned by the Editorial Office, Shanghai Chest. The article did not undergo external peer review.

Conflicts of Interest: The author has completed the ICMJE uniform disclosure form (available at http://dx.doi. org/10.21037/shc.2018.12.09). The author has no other conflicts of interest to declare.

Ethical Statement: The author is accountable for all aspects of the work in ensuring that questions related to the accuracy or integrity of any part of the work are appropriately investigated and resolved.

Open Access Statement: This is an Open Access article distributed in accordance with the Creative Commons Attribution-NonCommercial-NoDerivs 4.0 International License (CC BY-NC-ND 4.0), which permits the noncommercial replication and distribution of the article with the strict proviso that no changes or edits are made and the original work is properly cited (including links to both the formal publication through the relevant DOI and the license). See: https://creativecommons.org/licenses/by-nc-nd/4.0/.

\section{References}

1. Yuan A. Dr. Henning A. Gaissert: because tracheal surgical techniques remain imperfect, international cooperation is needed to strive for improvement. Asvide 2018;5:918. Available online: http://www.asvide.com/article/view/29067

(Science Editor: Amber Yuan, SHC, shc@amegroups.com) doi: 10.21037/shc.2018.12.09

Cite this article as: Yuan A. Dr. Henning A. Gaissert: because tracheal surgical techniques remain imperfect, international cooperation is needed to strive for improvement. Shanghai Chest 2018;2:100. 